\title{
An Evaluation of Chronic Asthma and Therapeutic Compliance Among Students at a Private University in South Africa
}

\author{
Viwe Dingani, Kagiso Maleka, Joris Oko Meye, Jonathan Rankin, Charity Rikhotso and Denise Wilson* \\ Faculty of Applied Science, Pearson Institute of Higher Education, Midrand, Gauteng, South Africa \\ *Corresponding Author: Denise Wilson, Faculty of Applied Science, Pearson Institute of Higher Education, Midrand, Gauteng, South \\ Africa.
}

Received: April 16, 2019; Published: October 04, 2019

DOI: $10.31080 /$ ASPS.2019.03.0411

\begin{abstract}
South Africa has the world's fourth highest number of deaths associated with asthma among people between 5 and 35 years of age. Asthma is a condition characterized a physiological response that results in the blockade of the pulmonary airways through triggers of bronchoconstriction and mucous secretion.

This observational study aimed to investigate the prevalence of asthma among Pearson Institute of Higher Education students on a single campus and to assess the related patterns of use of prescription medicines. Data were collected in the form of an electronic survey through the My Learning Management System (myLMS) platform to better reach the study population.

Descriptive statistics, bar charts and histograms were generated with Excel version 2016 in Microsoft Windows. The results showed that clinically diagnosed asthmatic students predominantly used inhalers containing beta subtype two ( $\beta 2$-) adrenergic agonists. Findings indicated a $45 \%$ chance of ashtmatic students complying with their treatment regimen and an $18 \%$ chance of these students co-using other drug treatments. Researchers concluded that the pattern of usage of asthma medicines by affected students increases the risk for asthma attacks. Tertiary institutions need to ensure they are equipped and prepared to respond to these incidents when they occur.
\end{abstract}

Keywords: Compliance; Asthma; B2-Adrenergic Agonist; Tertiary; University; Students

\section{Abbreviations \\ myLMS: my Learning Management System; $\beta 2$ ᄀ: Beta Subtype Two}

\section{Introduction}

Asthma is a chronic respiratory condition that is characterised by the narrowing of the airway or complete airflow obstruction due to inflammation and mucus secretion. Factors that trigger asthma include exposure to allergens or other environmental irritants [1], and exercise may exacerbate the condition [2]. Smoking and the use of alcohol has shown to affect asthma negatively, in that smoking may cause a decline in lung function and alcohol is associated with a change in the characteristics of airway mucus, smooth muscle regulation of airways diameter, and in bronchial blood flow [3].

The severity of the condition influences the frequency and seriousness of the general symptoms that patients experience during an asthma attack, which include coughing, wheezing, chest tight- ness, and shortness of breath [1]. Asthma is classified as persistent-severe, persistent moderate, persistent-mild and intermittent asthma4. In intermittent asthma experiences symptoms are experienced twice or less per day, persistent-mild asthma more than twice a day, moderate-persistent on a daily basis and persistentsevere asthma (also known as acute asthma) symptoms appear intermittently throughout the day [4].

The prevalence of this condition in South Africa, and the rest of Africa has risen, currently affecting 8-10\% of the South African population and $20 \%$ in Sub-Saharan Africa being affected [5]. The management of acute asthma includes prescribed medication, such as an inhaler (containing a beta type two ( $\beta 2$ ) -agonists), which is administered by the patient when experiencing symptoms [6]. Reliever medications, such as albuterol or salbutamol, are short-acting bronchodilators used as rescue therapies in patients, as needed, to relieve symptoms of acute asthma attack [7]. Salbutamol is a commonly used short-acting $\beta 2$ agonist formulated as a pressure me- 
tered dose, a dry powder, or a nebulizer [8], and causes the smooth muscle of the bronchioles to relax and open up9. This short-acting medication is preferred in mild asthma attacks in adults [9].

Controller medications, such as the standard therapy of inhaled corticosteroids (containing fluticasone and beclomethasone), manage inflammation in an effort to control the condition [7]. Alternately long-acting bronchodilators, such as salmeterol, or leukotriene modifiers, such as montelukast or zafirlukast, can regulate the response to asthma triggers [7].

The use of complementary or herbal medicines, is not unheard of for asthma, a study conducted in Brtiain indicated a high prevalence of using the herb Tylophora indica [10]. Another study evaluate the efficacy of traditional Chinese medicines, showing a decrease in asthma attacks in areas significantly affected by air pollution [11].

Patient compliance is essential for effective control of the condition. There are many factors to consider when assessing patient compliance, especially for a chronic disease, these range from not enough knowledge about the condition, age, gender, socioeconomic factors, non-compliance during remission, the side-effects of the medication, or even a preference for alternative medication [12].

In this study conducted at Pearson Institute of Higher Education, South Africa, the focus was on evaluating the chronic use of asthma medication among asthmatic students and associated compliance. The study also aimed at detecting any risk for drug-interactions that may worsen the condition.

\section{Methodology}

This study was an observational, cross-sectional study, carried out in the form of a survey at a single campus of Pearson Institute of Higher Education. The duration of the study was from April to May 2018. There were no strict exclusion criteria for participation in this survey study. Participants were asked to voluntarily take part in an internet survey that was distributed using the tertiary institution's communication medium, my Learn Management System (myLMS). myLMS is a site that is used to communicate announcements and enhance student access to relevant module information, academic or otherwise. The study was advertised by word-ofmouth and through a pop-up message on myLMS.

Internal ethical and scientific review of the protocol and surveyquestions was done, and participants were invited to participate in the study on a voluntary basis without further incentive. A consent notice was uploaded for student to assent to partake in the survey, to ensure understanding of the purpose of the study and to inform participants that their information would be kept anonymous. The questionnaire comprised of both closed- and open-ended questions, to reduce irrelevant information and inconsistencies, as well as to allow elaboration when required, respectively. The questions centred on the importance of external support, such as family members and friends, in maintaining therapeutic compliance, the comprehension of the disease and the medication options, compliance with package insert directions and doctors' prescription orders, lifestyle requirements and adjustments with living with asthma and daily habits such as exercise, smoking, and alcohol consumption.

The analysis procedures included summary descriptive statistics of the use of asthma medication among students. The results were generated using the population mean and sample standard deviation. Basic probability principles were used to express the chances of compliance among the participants.

\section{Results}

There were a total of 304 respondents across all faculties at Pearson Institute of Higher Education, which represented 8,64\% of the registered student body, of these 74 (24\%) participants were diagnosed with asthma previously. Contrary to what was expected, not all asthmatic students indicated that they were on medicine to treat their condition, with only $60(81 \%)$ on treatment. This may be due to a change in their condition, or that they are no longer experiencing attacks.

Basic probability statistics were used to indicate the likelihood of an asthmatic participants' level of compliance. Of the respondents, only 62 completed the questions on compliance and comprehension of the condition appropriately. Percentages calculated from the question asking the participant's level of compliance ranging from "do not comply" to "strongly comply" are in Table 1. It was found that 54 (73\%) of the participants indicated that they have full comprehension of their condition and treatment regimen, while only 20 (27\%) admitted to not understanding their condition. The association between a students' level of understanding of their condition and their self-indicated compliance status was evaluated. The levels of compliance were combined for convenience, 'strongly comply' and 'comply' were combined, and 'partially comply' was combined with 'do not comply'. Results showed the likelihood of finding participants who comply with their treatment regimen, as $45 \%$, with the probability for non-compliance as $54 \%$. This is an unexpected result, because researchers hypothesised that an increased knowledge on the condition would lead to higher levels of compliance. Table 2 shows that for the question 'Which medication are you using for asthma?', 50 asthmatic respondent use inhalers, one participant uses herbal medication, while nine do not use any medication. The remaining 14 respondents have incomplete answers, and was discarded as spoilt data.

Sixteen asthmatic participants indicated that they have comorbidities, such as diabetes and hypothyroidism, and 11 of these stated that they are on one of the following treatment in conjunction with their asthma therapy: dienogest, levothyroxine, iron, 
metformin, diclofenac, or paracetamol. The importance for asking whether they use other drugs for comorbidity was to evaluate the risk of drug-drug interactions. There is an $18 \%$ chance of finding an asthmatic taking asthma medication in conjunction with medication for another indication. A total of 18 participants responded inappropriately in this aspect of the survey, and this data is not reported.

This importance of support from family, friends, and medical staff for asthmatics was also assessed (Figure 1). The participants were asked to indicate on a sliding scale from 0 to $100 \%$ the level of importance of support in dealing with the condition. Majority of respondents, 25 (34\%), fell between the range 80 to $100 \%$, which indicates that they value support from their families, friends, and physicians when dealing with their asthma, while 17 (23\%) respondents of the participants were between 0 and 19\%- showing that they did not see the value in having external support in dealing with asthma. These results show that some level of support is required in order to deal with a condition such as asthma, which may influence a patient's lifestyle and daily activities.

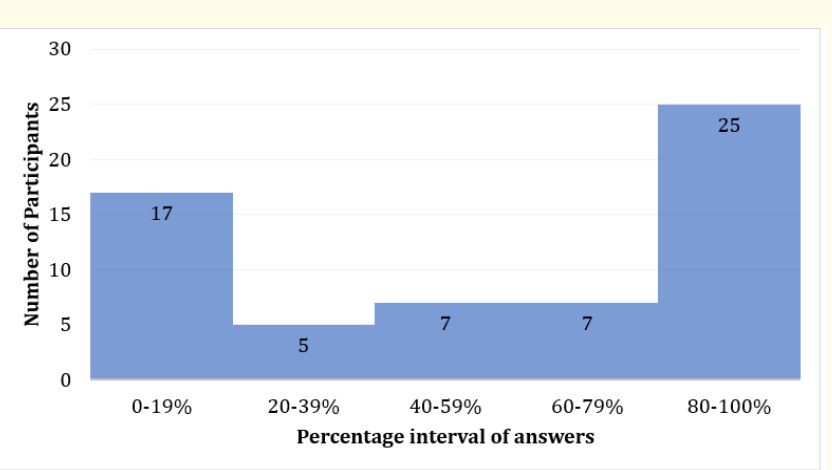

Figure 1: The perceived value of external support in patients living with asthma.

Participants were asked if they smoke, consume alcohol, or exercise, but correlation testing to ascertain whether these activities played any role in exacerbations of asthmatic attacks was not performed. As expected, the majority of the asthmatic participants were found to exercise less and they were also non-smokers (Figure 2).

\section{Discussion}

According to a study done at Sultan Qaboos University Hospital showed that 92 patients out of 218 receiving inhalers were compliant to the treatment [19], a similar distribution to our study. Results showed that there is a $45 \%$ (Table 1 ) chance of finding participants who comply with their treatment regimen and a $54.84 \%$ chance that more than half of the people surveyed do not comply fully to

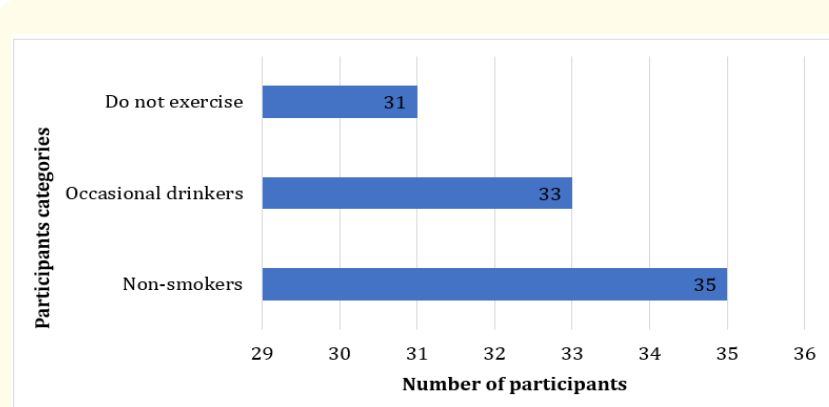

Figure 2: Factors that may influence asthma attack exacerbations.

their treatment. Inhalers were the most commonly used form of medication, as used by $68 \%$ of asthmatics (Table 2 ).

\begin{tabular}{|l|c|c|c|}
\hline $\begin{array}{c}\text { Compliance } \\
\text { Status }\end{array}$ & $\begin{array}{c}\text { Count } \\
\text { (Percentage) }\end{array}$ & $\begin{array}{c}\text { Level of com } \\
\text { prehension* }\end{array}$ & $\begin{array}{c}\text { Count } \\
\text { (Percentage) }\end{array}$ \\
\hline Compliant & $28(45 \%)$ & Good & $45(73 \%)$ \\
\hline $\begin{array}{l}\text { Non- } \\
\text { compliant }\end{array}$ & $34(54 \%)$ & Poor & $14(23 \%)$ \\
\hline TOTAL & $62(100 \%)$ \\
\hline $\begin{array}{l}\text { *Level of comprehension of their condition and treatment } \\
\text { regimen }\end{array}$
\end{tabular}

Table 1: Association between compliance and comprehension of asthma.

\begin{tabular}{|c|c|}
\hline Medication type & $\begin{array}{l}\text { Participants number } \\
\text { (percentage) }\end{array}$ \\
\hline Inhaler* & $50(68 \%)$ \\
\hline Herbal product & $1(1 \%)$ \\
\hline No therapeutic treatment ${ }^{+}$ & $9(12 \%)$ \\
\hline Total & $74(100)$ \\
\hline $\begin{array}{l}{ }^{*} \text { Different brand names but consist of } \\
\text { active ingredients such as ciclesonide, } \\
\text { salbutamol, and salmeterol: Alvesco } \\
\text { Foxair }^{\circledR} \text {, Asthmavent }{ }^{\circledR} \text {, Venteze } \\
\text {, } \text {, Ven- } \\
\text { tolin }^{\circledR} \text {. }{ }^{+} \text {Participants currently do not } \\
\text { use medication, possibly due to less } \\
\text { frequent asthma attacks. }\end{array}$ & \\
\hline
\end{tabular}

Table 2: Medications taken for asthma.

These results show the level of compliance, which is an important parameter as compliant participants generally have better control over their condition. From the categorical data in Figure 2, it seems asthmatics understand the limitations of their condition in that the majority of the participants are non-smokers and do not exercise, as both of these activities are known to exacerbate asthma. It then becomes questionable, if asthmatics understand their condition, then why are they non-compliant with their treatment regimen? Noncompliance factors may include not being covered 
by medical aid or other financial constraints that make medicines unaffordable or a lack of time to follow up with practitioners and to get medicine.

According to the results obtained, a small number of asthmatics co-use asthma medication with other medications. The concern of this result is that some medications can exacerbate asthmatic symptoms. One concern that we could identify is the co-use of non-steroidal anti-inflammatory drugs with asthma medication, as a person with aspirin-intolerant asthma may develop acute bronchoconstriction [14]. Furthermore, 11\% of asthmatics in this study were chronic smokers, which could limit their level of asthma control and lead to exacerbations when compared to nonsmokers [15]. It was seen that $34 \%$ of asthmatic participants were active participant in sports. A previous study saw that $90 \%$ of the subjects had airway narrowing and increased airway resistance during or after exercise [16].

According to Bielory., et al. there are herbal medicines that are used to treat asthma and one of the most common medicines used is Ephedra herba [13]. Only one respondent indicated that they had ever used a herbal remedy for their condition. The most commonly administered asthma medications amongst respondents was $\beta_{2}$ adrenergic agonists, with salbutamol being the most popular. This could be due to salbutamol's fast acting relief and few side effects at recommended doses [17]. According to Tsuji., et al. the use of a metered-dose inhaler is clinically preferred because it achieves effective bronchodilation within a relatively short period of time with fewer side effects; this agent is also used for asthma attacks and as prophylactic maintenance therapy [18].

\section{Conclusion}

The study found that from the sample population surveyed, those diagnosed with asthma mostly use $\beta 2$ adrenergic agonist inhalers. The majority of asthmatics were found to be non-compliant to their medication regimens. There was also a large prevalence of asthmatics co-using other medications for comorbidities. The majority of students indicated that external support improved their ability to handle their condition. Researchers identified a number of shortcoming in their study namely the lack of use of prevalence ratios, or similar tests, to establish associations between factors such as self-indicated compliance and level of understanding of therapy, or gender and compliance levels. Overall, due to the proposed level of non-compliance among asthmatic students to their treatment regimens, there is a substantial risk for asthma attacks and tertiary institutions should ensure they are equipped and prepared to respond.

\section{Acknowledgements}

The authors (VD, KM, JOM, JR, CR) declare that there is no conflict of interest, and that this study was completed as a requisite for their undergraduate degree in the module Introduction to Pharmacology. The authors would like to thank Mr. W. Fourie and his team at Pearson Institute for their assistance in the publication of the questionnaire to myLMS.

\section{Bibliography}

1. Kim H and Mazza, J. "Asthma". Allergy, Asthma and Clinical Immunology 7 (2011): S2.

2. Molis M and Molis W. Exercise-Induced Bronchospasm". Sports Health: A Multidisciplinary Approach 2 (2010): 311-317.

3. Kim 0 and Kim B. "Association of asthma symptoms with cigarette smoking and alcohol consumption in Korean adolescents". Nursing and Health Sciences 15 (2012): 65-72.

4. Dinsmore M. "The Effects of Exercise on Asthma and Quality of Life". Hdl.handle.net. (2018).

5. Van Blydenstein A., et al. "Factors affecting compliance and control of asthma in patients attending the Respiratory Outpatient Department, Chris Hani Baragwanath Academic Hospital". South African Respiratory Journal 21 (2015): 91.

6. Lalloo U., et al. "Guideline for the management of acute asthma in adults: 2013 update". South African Medical Journal 103 (2012): 189.

7. Sobieraj D and Baker W. "Medications for Asthma”. JAMA 319 (2018): 1520.

8. Cavkaytar Ö and Şekerel B. Salbutamol in asthma treatment: with nebulizer or inhaler?" Tuberkuloz ve Toraks (2012) 193198.

9. Billington C., et al. " 32 Agonists". Handbook of Experimental Pharmacology 237 (2016): 23-40.

10. Huntley A. "Herbal medicines for asthma: a systematic review". Thorax 55 (2000): 925-929.

11. Kopnina H. "Alternative Treatment for Asthma: Case Study of Success of Traditional Chinese Medicine Treatment of Children from Urban Areas with Different Levels of Environmental Pollution". ISRN Allergy (2012): 1-6.

12. Chapman K., et al. "Improving patient compliance with asthma therapy". Respiratory Medicine 94 (2000): 2-9. 
13. Bielory L., et al. "Clinical Efficacy, Mechanisms of Action, and Adverse Effects of Complementary and Alternative Medicine Therapies for Asthma". Allergy and Asthma Proceedings 25 (2014): 283-291.

14. Moon J., et al. "Aspirin-intolerant asthma in the Korean population: Prevalence and characteristics based on a questionnaire survey". Respiratory Medicine 107 (2013): 202-208.

15. To T., et al. "Results from a community-based program evaluating the effect of changing smoking status on asthma symptom control". BMC Public Health 12 (2012).

16. Eichenberger P., et al. "Effects of Exercise Training on Airway Hyperreactivity in Asthma: A systematic Review and MetaAnalysis". Sports Medicine 43 (2013): 1157-1170.

17. Ullmann N., et al. "Salbutamol and around". Italian Journal of Pediatrics 41 (2015): A74.

18. Tsuji A., et al. "Side Effects of Salbutamol Sulfate Delivered through a Metered-Dose Inhaler in a 14-year-old Boy with Bronchial Asthma". Japan: JMAL (2006): 81-83.

19. Baddar S., et al. "Asthma control: importance of compliance and inhaler technique assessments". Journal of Asthma 51 (2014): 429-434.

Volume 3 Issue 11 November 2019

(C) All rights are reserved by Denise Wilson., et al. 